of subjects into three overlapping volumes is an advantage. It should be possible to present all the information in a more compact, yet still legible, form. Every relevant department, and, as far as possible, every individual should appear, with a clear indication of the main research interests of each person. The subject index is badly in need of improvement, perhaps by controlling the main index terms and greatly increasing the amount of crossindexing. This presents great diffculties, but the compilers are in the Office for Scientific and Technical Information and might therefore be expected to do a little better. The present indices are somewhat lacking in both precision and accuracy.

Perhaps most important of all is a change in our attitude to works of this kind. All research workers (security considerations excepted) should consider it essential that details of their work should appear in the key directories. Those who finance their work might consider making this a condition of their grants. Only then will we have easy access to the facts we need to answer the many questions being raised today about the direction and utility of scientific research.

JEREMY WESTON

\section{Experimental Prebiology}

Origins of Life. By Cyril Ponnamperuma. Pp. $215+150$ illustrations, 20 in full colour. (Thames and Hudson: London, October 1972.) $£ 2.25$ cloth; $£ 1.25$ paper.

THIS stands out among the welter of recent books on the origin of life by being the smallest and best illustrated to appear. It is a book designed for the non-specialist, and it is a pleasure to welcome it as a conspicuous success. Ponnamperuma, speaking with the full authority of one of the world's foremost practitioners in the field of experimental prebiology, has nevertheless been able to express himself in language that is readily comprehensible to the nonchemist. For many years he was with NASA in the exobiology division; he is now at the University of Maryland as director of the laboratory of chemical evolution.

Ten of the sixteen chapters are devoted to aspects of chemical evolution, and it is refreshing to read not only of the successes of the past, but also of plans for future experimentation. The other six chapters comprehend investigations of meteorites, and deal with other aspects of exobiology. Some of these chapters are highly speculative, and almost escape the boundaries of science. Perhaps there are better accounts to be found elsewhere dealing with the fossil evidence, and with the possibility of intelligent life beyond the Earth. But there is no better account of the way that experimentation has illumined the processes of chemical evolution and our search for the origin of life.

The munificence of the illustrations can only be rivalled by other Thames and Hudson books in the same series. Chosen not by the author but by the publishers, they vary in relevance, and though they add much to the pleasure and interest of the volume, some are so inappropriate as to be misleading. What possible excuse can be found, for example, for illustrating a prebiotic site for the origin of life with a picture of the luxuriant vegetation of a tropical lagoon?

\section{P. C. Syluester-Bradley}

\section{Organophosphorus}

Organophosphorus Chemistry. By B. J. Walker. Pp. 278. (Penguin: Harmondsworth, Middlesex, October 1972.) $£ 3$.

As a subject like organophosphorus chemistry grows, and itself begins to divide into specialisms-and to disappear into the decent obscurity of specialist journals - the single volume text becomes more than ever indispensable. Dr Walker's book is aimed at the interested graduate student and the final year graduate (may his tribe increase) who is taking organophosphorus chemistry as a special topic and has $£ 3$ to spend.

To cover so broad a field in so small a space an author must have very clear ideas on what to leave out, and here Dr Walker's judgment is sound. $\mathrm{He}$ provides a competent mechanistic treatment of the most important areas, at the expense of any systematic approach to synthesis in this field. There is a good account of the use of various spectroscopic methods in Organophosphorus Chemistry, and extended coverage of two topics which are clearly of special importance. These are the Wittig reaction, where the author is expert and produces an excellent review, and phosphorus in biological processes, where he is not. This last is the weakest chapter in the book, and ranges over biological energy transfer and the structures of DNA and the various RNAs (including a reference to something called the codon), without any real attempt to relate them to the organophosphorus chemistry involved.

The author also falls foul of SI units. $\mathrm{He}$ gives bond lengths in metres, but the molecules unfortunately come out only one tenth of the usual size. After page 141 Angstrom units appear, with a correct length in metres given also; with the curious result that the P-C bond in ylids appears to be ten times longer than all the other bonds in the molecule. These are not typical, however, of a book which is fairly free of typographical errors and is attractively printed and produced. Sets of examples appear at the ends of chapters, and the bibliography is a model for any author, organized by topic, with a helpful brief description of each reference cited. The book can be recommended to the students for whom it is intended, and to libraries catering for them.

$$
\text { A. J. KIRBY }
$$

\section{Chemical Lists}

Chemical Substructure Index 1971. Annual Cumulative Edition. Part 1: Substructure Index A-Q, Users' Guide. Part 2: Substructure Index Q-9Y, Peptides. (Institute for Scientific Information: Pennsylvania and Uxbridge, Middlesex 1972.) N.p.

IN his searches for information from secondary journals, the average chemist depends largely on Chemical Abstracts with its wide area of coverage and its various indexes. But these virtues carry a penalty difficult to avoid-the time interval between publication in a primary journal and the appearance of the corresponding abstract.

To reduce this interval for some journals, the Institute for Scientific Information publishes Current Abstracts of Chemistry and Index Chemicus. It also provides other aids based on the same material, including computer tapes, programs, and printed lists, enabling information services of varying degrees of complexity to be set up by users themselves, according to their needs. One of these aids consists of a listing of all chemical compounds enumerated in Current Abstracts of Chemistry, the Chemical Substructure Index (CSI), which is produced monthly and cumulated annually to give the volumes under review.

The compounds are encoded into the Wiswesser Line Notation (WLN) and then listed alphanumerically in a permuted form under each significant symbol. There is also a "Quikscan" feature which indicates the presence of such symbols, although not their order. From this information, individual compounds or many part structures may be identified. In an attempt to ensure that search methods used will be correct, the listing is preceded by the notations for "Frequently Found Substructures", and by a CSI Users' Guide.

The encoders have produced notations of a good standard, and settle any problems arising in this connexion with WLN experts in the Chemical Notation Association, so that adverse criticism of the listing itself is not justified. 